ORIGINAL ARTICLE

\title{
On the advantage of sharing a holdfast: effects of density and occurrence of kin aggregation in the kelp Lessonia berteroana
}

\author{
Nicolás I. Segovia ${ }^{1,2}$, Julio A. Vásquez ${ }^{1}$, Sylvain Faugeron ${ }^{3,4}$ \& Pilar A. Haye ${ }^{1,5}$ \\ 1 Departamento de Biología Marina, Facultad de Ciencias del Mar, Universidad Católica del Norte \& Centro de Estudios Avanzados en Zonas \\ Áridas (CEAZA), Coquimbo, Chile \\ 2 Doctorado en Ciencias M/ Biología y Ecología Evolutiva, Departamento de Ciencias Ecológicas, Facultad de Ciencias, Universidad de Chile \\ 3 Centro de Conservación Marina, Facultad de Ciencias Biológicas, Pontificia Universidad Católica de Chile, Santiago, Chile \\ 4 UMI 3614 Evolutionary Biology and Ecology of Algae, CNRS, Sorbonne Universités UPMC Univ. Paris 06, Pontificia Universidad Católica de \\ Chile, Universidad Austral de Chile, \\ 5 Interdisciplinary Center for Aquaculture Research (INCAR), Universidad de Concepción, Concepción, Chile
}

\begin{abstract}
Keywords
Density dependence; fusion of individuals; genetic relatedness; kelp; kin aggregation; kin selection; microsatellites.

\section{Correspondence}

Pilar A. Haye, Departamento de Biología Marina, Facultad de Ciencias del Mar, Universidad Católica del Norte \& Centro de Estudios Avanzados en Zonas Áridas (CEAZA), Larrondo 1281, Coquimbo, Chile. E-mail: phaye@ucn.cl
\end{abstract}

Accepted: 24 June 2014

doi: 10.1111/maec.12206

\begin{abstract}
We investigated the density-dependent and genetic relatedness that regulate the occurrence of inter-individual (genet) fusion forming plurigenotypic organisms in the brown alga Lessonia berteroana. Recruitment generally occurs at high densities in the inter-tidal, allowing contact of neighbouring holdfasts as they grow and expand on the substrate. Algal density, by contrast, is regulated by the effects of herbivory and wave impact, which often lead to low holdfast density. Herein, we investigated whether the occurrence of plurigenotypic organisms and their genotypic composition (number of genotypes per plurigenotypic organism) are density dependent and affected by kin selection in the inter-tidal kelp L. berteroana. Four microsatellite loci were used to analyse DNA from 260 samples obtained from shared and non-shared holdfasts, at two sites with high and two site with low holdfast density. Analyses showed that fusions forming plurigenotypic organisms are extremely common. Interestingly, the frequency of fusions was higher in low-density sites, in which $100 \%$ of the plants had at least two genotypes and the average was 3.5. In high-density sites, $62 \%$ of plants were plurigenotypic, with an average of 2.8 genotypes per plant. Additionally, we found that genotypes that shared a holdfast had a significantly higher genetic relatedness than the average in the population, compatible with a kin structure. Density dependence and kin structure suggest that the occurrence of plurigenotypic organisms is linked to environmental quality, and that kin or multilevel selection may be favouring the fusion of genetically related genets.
\end{abstract}

\section{Introduction}

Different units of relevance for ecological and evolutionary processes can be delineated, such as the population, the family or group of related individuals, the colony and the individual organism. As most of these units can actually be nested one into the other (e.g. individuals into colonies or families, colonies into populations; see
Nachtomy et al. 2002), the limits of the individual, as a basic ecological and evolutionary unit, are sometimes difficult to define. In fact, individuals of many species live in groups in which they find both protection against environmental stresses (e.g. predation) and closeness to other individuals for reproduction. The case of clumps and colonies is particularly interesting because the functional limits between the genet, issued from a single 
fertilized egg, and the individual organism that is made of a mixture of different genets, are most often indistinguishable. Such findings have stimulated important debate around the concept and definition of the individual and the organism (e.g. Santelices 1999; Nachtomy et al. 2002; Pepper \& Herron 2008). Clumps have been reported in a wide variety of taxa, some of which are algal species (Santelices et al. 1996, 1999, 2003; Wernberg 2005; González \& Santelices 2008). In red algae, fusion of individuals results in a chimeric, plurigenotypic organism (PO), with complete loss of individual identity (Paine 1990; Santelices et al. 1996, 1999). This process, known as coalescence in red and green algae (not formally described in brown algae), is difficult to study in natural populations because it occurs mainly at early microscopic stages (e.g. spores or sporelings; Santelices et al. 1996, 1999; Santelices \& Aedo 2006). As a consequence, the factors that regulate the fusion of genets have scarcely been explored.

Two non-exclusive hypotheses can be proposed to explain the occurrence of fusions at the holdfast level in algal species: (i) fusions are correlated with density of recruits, which, during their development, grow and eventually get into such close contact with their neighbours that they fuse together (i.e. they integrate their cell lines into a single tissue) or (ii) fusions are regulated by fitness differences between clumped and isolated genets. In the first case, fusions are just a density-dependent process whereas selection and adaptation can be invoked in the second hypothesis. Evidence based on higher survival rates of aggregates compared with isolated individuals of red and brown algae suggests a selective advantage of clumping (Wernberg 2005; Santelices \& Aedo 2006; Santelices \& Alvarado 2008). For instance, holdfast aggregations of the kelp Ecklonia radiata have been observed at higher frequencies in exposed areas than in more protected ones, suggesting that aggregation reduces mortality from dislodgement in exposed areas (Wernberg 2005).

Based on field observations of tagged sporophytes, Vásquez et al. (2008) and Rodriguez et al. (2014) showed that fusions of individuals forming a PO might be recurrent in the kelp Lessonia berteroana Montagne (formerly Lessonia nigrescens, González et al. 2012). This species dominates the low inter-tidal rocky shores of Chile and southern Peru (Hoffmann \& Santelices 1997) and its structure consists of a massive holdfast attached to the rocky substrate. A variable number of stipes emerge from the holdfast. Stipes have branches and each branch carries one frond distally. Holdfasts grow vertically and horizontally leading to contact between neighbours that progressively grows, resulting in their tissues mixing and forming a single unit that externally mimics a single organism (Vásquez et al. 2008). A simple expectation from this growth pattern is that the rate at which genets fuse increases with density (Rodriguez et al. 2014). However, if fusions confer some kind of advantage under stressful environmental conditions, then the occurrence of fusions should increase when the environment moves away from optimal conditions for the species.

To test these predictions, we quantified the number of different genets (i.e. multilocus microsatellite genotypes) per plant (stipes and fronds of a single holdfast) of L. berteroana under two contrasting densities of holdfasts in one natural population.

In L. berteroana, density variability, spatial distribution, establishment of new recruits, mortality rates and growth patterns are regulated mainly by herbivory, wave impact and intra-specific competition for hard substrate (Ojeda \& Santelices 1984; Santelices \& Ojeda 1984). The strengths of these three selective agents differ in association with distance between holdfasts. For instance, herbivory increases with distance between holdfasts (Vásquez \& Santelices 1990), which in turn reduces the net recruitment of L. berteroana (Ojeda \& Santelices 1984; Camus 1994). These patterns result in a general negative relationship between kelp coverage and herbivore abundance (Broitman et al. 2001), and pinpoint herbivory as a strong density-dependent selective pressure on $L$. berteroana. Wave impact is another major cause of mortality in benthic algae (Dayton et al. 1975; Vadas et al. 1990) that is considered a selective agent driving morphological and physiological adaptation (Vásquez 1992; Blanchette 1997; Martínez \& Santelices 1998). Wave impact also imposes a high dynamic pressure that can result in dislodgement or removal of settled plants (Vadas et al. 1990, 1992). In close holdfast proximity, the interaction between water motion and the shape of the stipes and fronds produces a wave movement known as the whiplash effect (WE, sensu Dayton 1975). Owing to the WE, high holdfast density is beneficial for kelp populations, allowing the persistence of new recruits (Ojeda \& Santelices 1984). Vásquez (1995) showed that when the distance between holdfasts exceeds $2 \mathrm{~m}$, the WE is reduced (i.e. the environment is less protective), increasing herbivory. Thus, both herbivory and the WE have density-dependent effects in both inter-tidal and subtidal Lessonia species (e.g. Lessonia trabeculata, Vásquez 1992; Vásquez \& Buschmann 1997) that lead to greater survival of plants at high holdfast density.

High holdfast density implies intra-specific competition for substrate and light, limiting the settlement of new recruits (Santelices \& Ojeda 1984; Andrew \& Viejo 1998; Steen \& Scrosati 2004). In this context, fusions between conspecifics may be seen as a way to increase individual density without increasing substrate occupancy and to avoid intra-specific competition. This kind of strategy has 
been found more frequently between kin than unrelated individuals (Gerlach et al. 2007; Lizé et al. 2012). For example, plants effectively experience strong social interactions and kin recognition to varying physiological and morphological responses depending on the identity of the neighbour (de Kroon 2007; Biedrzycki et al. 2010; Wu et al. 2013). However, as Hamilton's (1964) rule predicts, fusions may be an adaptive trait only if the benefits outweigh the costs, and close contact amongst individuals within a holdfast is likely to induce strong competition amongst them (Novoplansky 2009). This cost can probably be reduced if fusion occurs amongst relatives, so that benefits are expressed in terms of inclusive fitness (i.e. the direct contribution of each genotype to the next generation's gene pool plus their indirect contribution through the progeny of their relatives). Therefore, if fusion between relatives enhances survival rate, then positive kin selection is a likely explanation (File et al. 2013). In this context, fusions between relatives in L. berteroana would be more frequent in low-quality environments (i.e. low density) in which isolated individuals (unigenotypic organisms) may not persist.

The goal of this study was to shed light onto the factors that regulate the fusion of genets into a single organism, by assessing genetic diversity of holdfasts at low and high plant densities and the genotypic relatedness within plants in the kelp L. berteroana.

\section{Material and Methods}

\section{Sampling, field measurements and DNA extraction}

Tissues of Lessonia berteroana were sampled in an extensive inter-tidal kelp bed in Lagunillas, Chile $\left(30^{\circ} 06^{\prime} \mathrm{S}\right.$, $71^{\circ} 22^{\prime} \mathrm{W}$ ) on areas showing no evidence of recent kelp harvest. In order to test for density dependence, 12 plants of different sizes were sampled in two sites of low holdfast density (LD: $0.5-1$ holdfasts $\mathrm{m}^{-2}$ ) and two of high holdfast density (HD: 5-8 holdfasts $\cdot \mathrm{m}^{-2}$ ). We use the term plant to refer to the organism identifiable macroscopically on the shore, and which may be made of either a single or multiple genets.

From each of the 48 sampled plants, six tissue samples were collected each from a different stipe selected at random, except for some small plants (i.e. fewer than six stipes). In these cases, the samples were taken from all the available stipes (at least five). Fresh tissue samples of $2 \mathrm{~cm}$ in diameter were collected from the base of fronds avoiding reproductive tissue and epiphytes. Collected pieces were dried using paper towel, placed in sealed individual bags with silica gel and stored at room temperature until DNA extraction. DNA was extracted from 30-40 mg of dried powdered tissue using a slightly modified version of the cetyltrimethyl ammonium bromide DNA extraction adding polyvinyl pyrolidone in order to remove polyphenols (Martínez et al. 2003). Extracted DNA was quantified in a spectrophotometer (NanoDrop Technologies, Wilmington, DE, USA) and kept at $-20{ }^{\circ} \mathrm{C}$.

To account for the effect of plant size on the frequency of fusions, three plant-to-plant morphometric values were recorded for each sampled plant: maximum length, holdfast diameter and number of stipes. In brown algae, growth is highly related to microhabitat conditions; thus, kelp size is not necessarily related with age. In order to consider genet-to-genet morphology, i.e. differences within the plant, for each sampled stipe, we recorded the length, diameter and number of dichotomies.

\section{Informative microsatellite loci determination}

To evaluate which loci were informative for the study, 10 DNA samples from different plants were randomly picked to explore eight microsatellite loci available for Lessonia berteroana (Faugeron et al. 2009). PCRs were performed in a final volume of $20 \mu \mathrm{l}$ with: $1.5 \mathrm{ng}$ DNA, $2 \mathrm{~mm}$ of $10 \times$ buffer, $0.6 \mathrm{~mm}$ dNTP mix, $1.8 \mathrm{~mm} \mathrm{MgCl}_{2}, 0.2 \mathrm{~mm}$ of each primer, $0.075 \mathrm{mg} \cdot \mathrm{ml}^{-1}$ of bovine serum albumin and 0.2 U Taq DNA polymerase (Fermentas, Vilnius, Lithuania). Temperature cycling consisted of an initial soak of $3 \mathrm{~min}$ at $95{ }^{\circ} \mathrm{C}$, then 10 touchdown cycles at $95{ }^{\circ} \mathrm{C}$ for $45 \mathrm{~s}$, $60-63{ }^{\circ} \mathrm{C}$ for $45 \mathrm{~s}$ and an extension of $45 \mathrm{~s}$ at $72^{\circ} \mathrm{C}$. Following this, 30 cycles at $95{ }^{\circ} \mathrm{C}$ for $45 \mathrm{~s}, 50{ }^{\circ} \mathrm{C}$ for $45 \mathrm{~s}$, $72{ }^{\circ} \mathrm{C}$ for $45 \mathrm{~s}$ and a final extension of $72{ }^{\circ} \mathrm{C}$ for $7 \mathrm{~min}$ were performed. Amplicons were genotyped in an $\mathrm{ABI}$ Prism 3700 (Applied Biosystems, Foster City, CA, USA) and the electrophenograms were visualized using GENEMARKER v. 1.81 (SoftGenetics, State College, PA, USA).

The main criteria for considering loci as informative were the degree of polymorphism in the local population and PCR amplification success. After checking for polymorphism, genotypes were analysed in MICROCHECKER 2.2 (Van Oosterhout et al. 2004) to determine the probability of null alleles. The probability of finding the same multilocus genotype by chance twice in each site of each density was calculated with GENEALEX v. 6 (Peakall \& Smouse 2006). It was considered a sufficient number of informative loci when each of the 10 analysed DNA samples had different multilocus genotypes.

\section{Multilocus genotype data analyses}

Any holdfast with more than one multilocus genotype was considered a PO. The effects of size and density were analysed using generalized linear mixed models (GLMMs) with Poisson errors implemented in the lme4 package in the software $\mathrm{R}$ ( $\mathrm{R}$ Core Team 2013). GLMMs are 
appropriate for non-normal data influenced by fixed and random effects (Crawley 2005; Bolker et al. 2008; Grueber et al. 2011). In each model, effects of plant morphometric values (MV) (holdfast diameter, total length and total number of stipes) and density (low and high, denoted as $\mathrm{LD}$ and HD, respectively) in the occurrence of POs, and their interaction, was evaluated using each of the three MV as co-variables with the site (St) nested in density. The correlation between plant length and holdfast diameter is well known in Lessonia (Santelices 1982; Vásquez \& Santelices 1984; Vásquez 1991); however, the correlation of these variables and the number of stipes is not consistent and only occurs when reproductive stipes are considered (Vásquez 1991). Finally, differences in the number of genotypes between densities were evaluated in a single GLMM using density (D) as categorical variable following the same structure as the previous models.

Strictly, site is a random effect because all levels of that factor are selected as a random sample from all possible levels (sites) that could be included in the study area (spatial pseudoreplication). So additionally, as an exploratory analysis of the relative importance of the factors in the models, according to the Akaike information criterion (AIC), the site effect was evaluated as an explanatory variable with fixed effects, and in interaction with variables that e tGLMMs showed to have a significant effect on the number of genotypes.

Lastly, principal component analyses (PCAs) and lineal discriminant analysis (LDA) were carried out with the logtransformed data of the three genet-to-genet variables (length, diameter of the stipe and number of dichotomies) and the three plant-to-plant MV variables (holdfast diameter, total length, number of stipes). The objective of these analyses was to observe possible differences in both densities considering genet-to-genet variance as a way to include the morphological differences within the plant and plantto-plant differences between densities. Both analyses were carried out using the MASS package, and the 95\% confidence ellipses were calculated with the ELLIPSE package, both available in the CRAN R project (R Core Team 2013).

\section{Relatedness amongst fused genets}

To investigate the occurrence of kin aggregations within a PO, we tested whether genotypes sharing a holdfast were genetically closer than on average in the population. This was achieved by comparing the average pairwise coefficient of relatedness R (Ritland 1996) of each plant with the average inter-plant pairwise $\mathrm{R}$. The upper limit of the one-tailed 95\% confidence interval for inter-plant Rvalues for each site was determined by bootstrapping in $\mathrm{R}$ (R Core Team 2013) 10,000 values of mean R amongst 10 randomly sampled (with replacement) pairwise $\mathrm{R}$-values obtained from pairs of genotypes from different plants. Observed intra-plant mean R-values that were higher than the 95\% limit were considered to represent a significantly higher genetic relatedness than the background population.

\section{Results}

\section{Informative microsatellite loci identification}

Of the eight explored microsatellite loci, four (Less1T11, Less2D22, Less2D25 and Less2D26) were polymorphic enough to unequivocally identify each of the 10 preliminary sampled individuals, and thus were selected to characterize all samples. The probability of finding the same multilocus genotype twice by chance using these four loci was $9.07 \times 10^{-5} \pm 0.0004$ and $0.001 \pm 0.020$ for LD and $\mathrm{HD}$, respectively.

\section{Fusion of individuals in Lessonia berteroana}

Of the 260 tissue samples analysed, from 48 plants, 150 corresponded to different individuals based on multilocus genotypes, which correspond to a total of 39 plurigenotypic organisms (81.3\% of the sampled holdfasts). There was an average of 3.17 multilocus genotypes per plant, of a maximum of six that could be detected with the sampling scheme. Only $18.5 \%$ of the sampled holdfasts showed only one multilocus genotype. By contrast, 22.9\% showed at least five different multilocus genotypes, including small kelps (i.e. all five stipes with a different multilocus genotype; Fig. 1).

The evaluation of the effects of plant-to-plant MV using GLMMs revealed that neither total length nor holdfast diameter influenced the number of genotypes per holdfast (df: $41, \mathrm{P}=0.1130$ and 0.1891 , respectively), even when interacting with density (df: 41, $\mathrm{P}=0.0970$ and 0.0879 , respectively) (Table 1 ). Interestingly, the number of genotypes varied significantly with the number of stipes per holdfast (df: $41, \mathrm{P}=0.00721$ ) with a significant effect of density in this model (df: 41, $\mathrm{P}=0.00261$ ), although the interaction of density with the MV was not significant (df: 41, $\mathrm{P}=0.15932$ ) (Table 1). The effect of the size, particularly with the number of stipes as the response variable was significant only at $\mathrm{HD}$, whereas at $\mathrm{LD}$ there was no relationship (Fig. 2). Moreover, holdfast density had a significant effect on the average number of genotypes per holdfast (df: 41, P = 0.0036; Table 1). At LD 100\% of the holdfasts were plurigenotypic, whereas only $62.5 \%$ were at HD. The average number of genotypes was also greater at LD, with 3.54 genotypes per holdfast, versus 2.79 genotypes per holdfast at HD. This suggests that plant density 


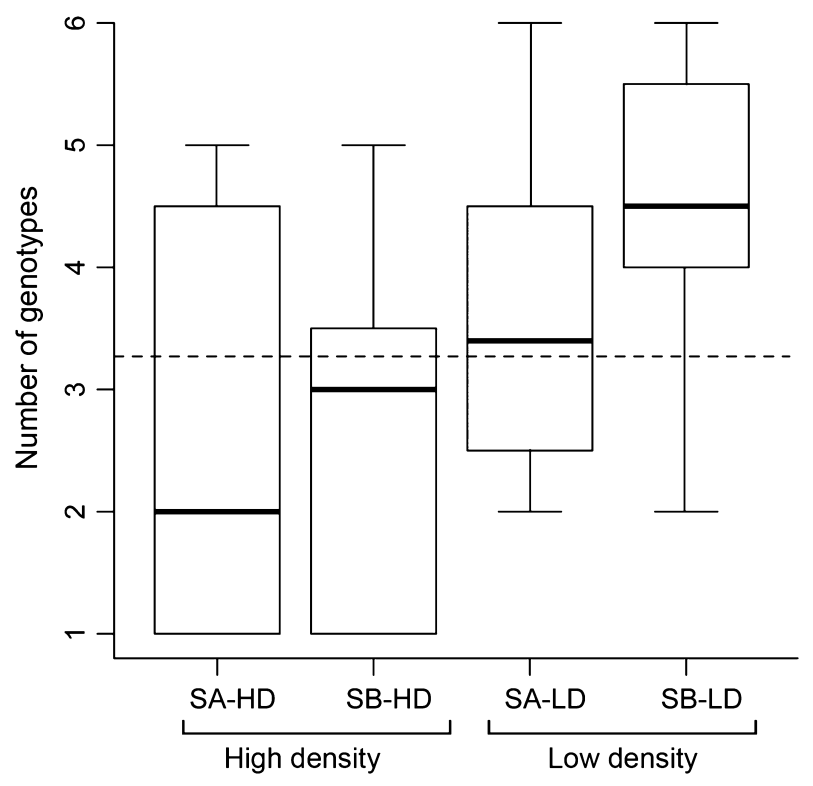

Fig. 1. Box-plot of numbers of multilocus genotypes per plant detected at two sites (SA and SB) with high (SA-HD and SB-HD) and two with low holdfast densities (SA-LD and SB-LD) in Lessonia berteroana. The dashed horizontal line indicates the global average of multilocus genotypes.

Table 1. Summary of the generalized linear mixed models using morphometric values of the plants. The table shows the results of comparing high $(\mathrm{H})$ versus low $(\mathrm{L})$ holdfast density.

\begin{tabular}{|c|c|c|c|c|}
\hline Model & Estimate & SE & Z-value & P-value \\
\hline \multicolumn{5}{|c|}{$\mathrm{Ng}=\mathrm{D} \times$ number of stipes $+\mathrm{St}(\mathrm{D})(\mathrm{AIC}: 35.79)$} \\
\hline Intercept & 0.601 & 0.191 & 3.137 & $>0.001$ \\
\hline Density $(\mathrm{H}-\mathrm{L})$ & 0.780 & 0.259 & 3.010 & $0.003 *$ \\
\hline Number of stipes & 0.018 & 0.006 & 2.687 & $0.007 *$ \\
\hline $\begin{array}{l}\text { Density } \mathrm{H}-\mathrm{L} \times \text { number of } \\
\text { stipes }\end{array}$ & -0.018 & 0.013 & -1.407 & 0.159 \\
\hline \multicolumn{5}{|c|}{$\mathrm{Ng}=\mathrm{D} \times$ total length $+\mathrm{St}(\mathrm{D})(\mathrm{AIC}: 37.96)$} \\
\hline Intercept & 0.527 & 0.297 & 1.772 & 0.076 \\
\hline Density $(\mathrm{H}-\mathrm{L})$ & 0.609 & 0.367 & 1.660 & 0.097 \\
\hline Total length & 0.003 & 0.002 & 1.585 & 0.113 \\
\hline $\begin{array}{l}\text { Density } \mathrm{H}-\mathrm{L} \times \text { total } \\
\text { length }\end{array}$ & -0.001 & 0.002 & -0.376 & 0.706 \\
\hline \multicolumn{5}{|c|}{$\mathrm{Ng}=\mathrm{D} \times$ holdfast diameter $+\mathrm{St}(\mathrm{D})(\mathrm{AIC}: 38.14)$} \\
\hline Intercept & 0.558 & 0.322 & 1.730 & 0.083 \\
\hline Density $\mathrm{H}-\mathrm{L}$ & 0.622 & 0.364 & 1.706 & 0.087 \\
\hline Holdfast diameter & 0.028 & 0.021 & 1.313 & 0.189 \\
\hline $\begin{array}{l}\text { Density } \mathrm{H}-\mathrm{L} \times \text { holdfast } \\
\text { diameter }\end{array}$ & -0.011 & 0.023 & -0.466 & 0.641 \\
\hline
\end{tabular}

$\mathrm{Ng}=$ number of genotypes; $\mathrm{D}=$ density; $\mathrm{St}=$ sites; $\mathrm{AIC}=$ Akaike information criterion.

*Significant values $(P<0.05)$.

explains the observed data better than MV; a marginal association between number of stipes and number of genotypes could be observed only at HD (Fig. 2).
Table 2. Summary of the generalized linear mixed model testing the effect of density (D) on the number of genotypes $(\mathrm{Ng})$.

\begin{tabular}{lcccr}
\hline Model & Estimate & SE & Z-value & P-value \\
\hline $\mathrm{Ng}=\mathrm{D}+\mathrm{St}(\mathrm{D})$ & $($ AIC: $22.2, \mathrm{df}=5, \mathrm{k}=3)$ & & \\
Intercept & 0.9328 & 0.1280 & 7.286 & $<0.001^{*}$ \\
Density & 0.4535 & 0.1637 & 2.769 & $0.006 *$ \\
\hline
\end{tabular}

St $=$ sites; $\quad$ AIC = Akaike information criterion; $k=$ number of variables.

*Significant values $(\mathrm{P}<0.05)$.

Exploring the relative weights of each factor in the models considering the site $(\mathrm{St})$ as a fixed predictor, the model of the interaction of size and density showed low values in terms of relative weights (according to the AICs, Table 2), suggesting that density and size did not act together as explanatory variables on the occurrence of POs and the number of genotypes per holdfast. Site-tosite density variations seem to explain the differences between the number of POs and number of genotypes per PO in each model (Fig. 1).

In the PCA analyses, using genet-to-genet morphological variables, the first two axes explained $95.67 \%$ of the total variance. The first axis was composed of the three variables that had similar loadings, and the second axis mainly of stipe diameter, suggesting that the three genetto-genet variables are associated with morphological variation between densities. The PCA showed two groups with an overlap of a few genets that were significantly differentiated (one-way ANOVA; $\mathrm{F}_{1,258}=52.59, \mathrm{P}<10^{-12}$; Fig. 3). In this analysis, the results showed that genets at LD are in general smaller than at HD. The trend is more evident for stipe diameter, which tends to be thinner at LD than HD. The LDA approach, with one canonical discriminant function (i.e. two classes: HD and LD), showed that stipe diameter was the variable with the highest discriminant coefficient. This discriminant function was able to correctly assign $89.7 \%$ of the samples to their density. Wrong predictions were in almost all cases (except for one) for HD samples assigned as LD. By contrast, using plant-to-plant MV, the PCA showed only one undistinguishable group and the LDA could correctly assign the plant to the density of origin in $47.9 \%$ of cases.

\section{Relatedness analyses}

From a total of 39 POs, 15 at $\mathrm{HD}$ and 24 at LD, 30 (i.e. $77 \%$ ) displayed an intra-plant mean relatedness significantly higher than expected given the inter-plant pairwise relatedness in the population (Table 3 ). From these 30 holdfasts, $66.6 \%$ occurred at $\mathrm{HD}$ and $79.16 \%$ at LD. There was strong heterogeneity in intra-plant relatedness: site $\mathrm{A}$ in HD (SA-HD) had the lowest number of plants 


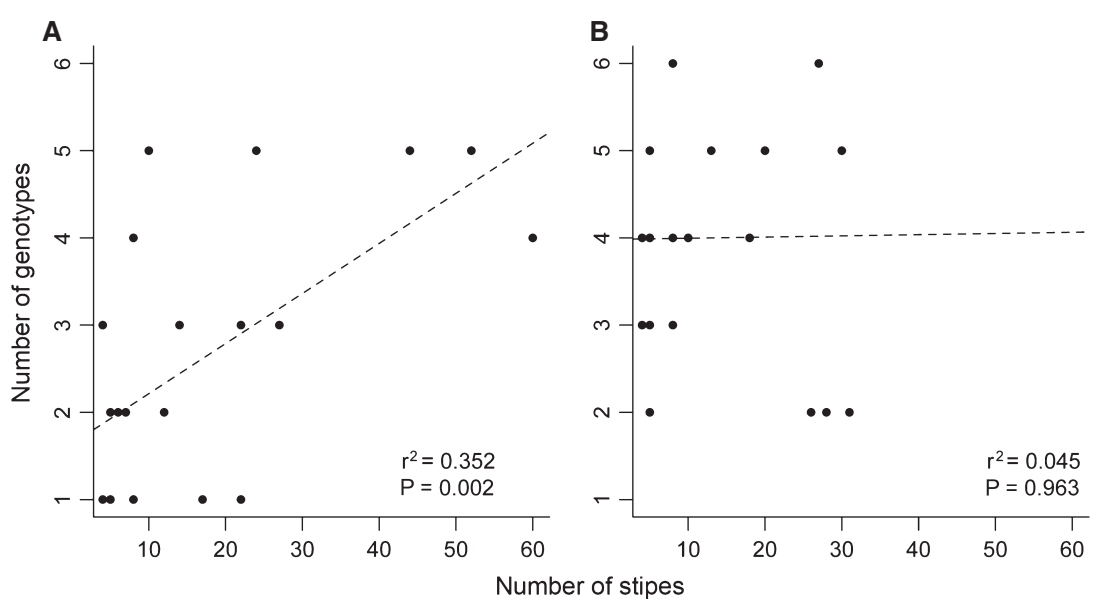

Fig. 2. Relationship between the number of multilocus genotypes per plant and the number of stipes at high (a) and low (b) holdfast density in Lessonia berteroana.

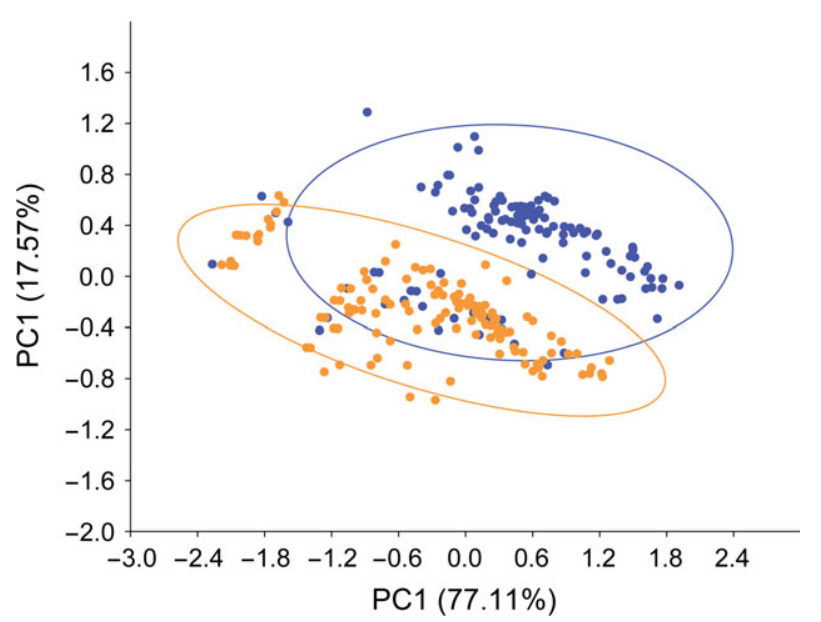

Fig. 3. Bivariate plot of scores from principal components 1 (PC1) and 2 (PC2) of a principal components analysis of the 260 sampled genets of Lessonia berteroana and three genet-to-genet morphological values of stipes (length, diameter and number of dichotomies). Blue points are low density and orange points are high density; the 95\% confidence ellipses for each group are shown.

(three out of seven) with significantly higher mean relatedness than the population level, whereas every PO in site B (SB-HD) displayed a significantly higher intra-plant mean $\mathrm{R}$ (Table 3). At $\mathrm{LD}$, where relatedness is more common, most intra-holdfast pairwise R-values were significant, with only two and three POs from SA-LD and SB-LD, respectively, with values within the expected range of inter-plant values.

\section{Discussion}

\section{Occurrence of plurigenotypic holdfasts}

Our results indicate that the formation of POs in Lessonia berteroana is a very frequent phenomenon. Thirty-nine of the 48 analysed plants had at least two different genets. As for a number of red and green coalescing algae (Santelices et al. 1999, 2003), fusion of L. berteroana at the holdfast level results in a single macroscopic organism in which the different genets are indistinguishable (Rodriguez et al. 2014). The average number of genotypes per holdfasts was surprisingly high, with 11 out of 39 POs bearing at least five genotypes. Together with the observation that fusions were more frequent in LD than in HD areas, the results indicate that the occurrence of fusions is not a simple consequence of holdfast proximity. Therefore, fusions do not occur during the plants' ontogeny, but instead as a consequence of reduced space when plants grow and the increased distance between plants. Rodriguez et al. (2014) showed that the coalescence in L. berteroana is a continuous process in which recruits may fuse with other isolated recruits or groups, or even with adults and senescent plants.

This has been proved to explain the early benefits of coalescence in microscopic stages of red algae (Santelices et al. 1996; Santelices \& Aedo 2006), which show a positive relationship between the number of coalescing spores and the probability of survivorship (Santelices et al. 1999; Santelices 2001, 2004). Small plants (i.e. fewer than five stipes) of L. berteroana were found at both densities, but at LD every small plant is formed of up to five multilocus genotypes, giving further support for the early selection of POs against unigenotypic organisms at LD. By contrast, high densities seem to result from the survival of both uni- and plurigenotypic organisms, at least during the early stages of kelp growth.

There are three main ways of coalescing at the microscopic stages of kelps: (i) aggregated settlement of spores within a few $\mathrm{mm}^{2}$, producing a single PO that is observable with the naked eye; (ii) recruitment of spores on top of established holdfasts; and (iii) vegetative ramification of the female gametophyte that then produces multiple 
Table 3. Estimates of intra- and inter-plant pairwise relatedness R-values. The number of sampled plants with more than one genotype is given in parentheses after each R-value.

\begin{tabular}{|c|c|c|c|c|}
\hline & $\mathrm{SA}-\mathrm{HD}$ & SB-HD & SA-LD & SB-LD \\
\hline \multirow[t]{12}{*}{ Intra-plant pairwise R-values } & $0.046 *(10)$ & $0.215 *(5)$ & $0.058 *(37)$ & $0.065 *(1)$ \\
\hline & $-0.006(11)$ & $0.094 *(7)$ & $0.030(38)$ & $0.094 *(3)$ \\
\hline & $0.023(24)$ & $0.624 *(8)$ & $0.318 *(39)$ & $0.077 *(4)$ \\
\hline & $0.124 *(27)$ & $0.233 *(15)$ & $0.058 *(40)$ & $0.174 *(6)$ \\
\hline & $0.027(28)$ & $0.026 *(16)$ & $0.046 *(41)$ & $0.049 *(13)$ \\
\hline & $0.024(32)$ & $0.300 *(17)$ & $0.892 *(42)$ & $0.033(22)$ \\
\hline & $0.211 *(33)$ & $0.088 *(19)$ & $0.071 *(43)$ & $0.041(29)$ \\
\hline & & $0.360 *(20)$ & $-0.014(44)$ & $0.172 *(31)$ \\
\hline & & & $0.077 *(45)$ & $-0.059(34)$ \\
\hline & & & $0.283 *(46)$ & $0.084 *(35)$ \\
\hline & & & $0.478 *(47)$ & $0.058 *(39)$ \\
\hline & & & $0.941 *(48)$ & $0.338 *(50)$ \\
\hline $\begin{array}{l}\text { One-tailed } 95 \% \text { confidence interval } \\
\text { for inter-plant pairwise R-values }\end{array}$ & -0.123 to 0.029 & -0.149 to 0.020 & -0.169 to 0.046 & -0.144 to 0.042 \\
\hline
\end{tabular}

$S A=$ site $A ; S B=$ site $B ; H D$ = high density; $L D=$ low density.

$*$ Values significantly higher than expected from one-tailed $95 \%(P<0.05)$ confidence interval of mean inter-plant pairwise R-values.

eggs (Avila et al. 1985) that may be fertilized by different males. The present study was not designed to discriminate amongst these possibilities. However, two major findings of this study allow inferring on the causes of the fusions. On the one hand, aggregated settlement should vary amongst sites and be negatively correlated to population density in order to explain the higher occurrence of POs at LD than at HD. On the other hand, multiple paternities in a single ramified female gametophyte should create half-sib relatedness, increasing the degree of genetic relatedness amongst genotypes within a plant, compared with the population. Alternatively, both aggregated and non-aggregated settlements occur everywhere, but only closely settled gametophytes survive and reproduce. These points are discussed in the following sections.

Fusions of individuals as an environmentally mediated process

The occurrence of intra-specific fusion in Lessonia berteroana appears to be strongly correlated with environmental quality, as well as in other kelps (Malm \& Kautsky 2004; Wernberg 2005). Indeed, differences in population density of L. berteroana result from environmental quality, which is heterogeneous, and optimal conditions favour high densities. However, the negative correlation between holdfast density and occurrence of POs strongly suggests that POs have certain advantages over non-POs in sub-optimal conditions, i.e. in low-density areas. Unigenotypic organisms only occur at $\mathrm{HD}$, accounting for $75 \%$ of the small plants with fewer than five stipes, suggesting that optimal environmental conditions allow recruitment and survival of the different kinds of organisms (uni- and plurigenotypic), as opposed to LD. Similar results were obtained by Malm \& Kautsky (2004) for Fucus vesiculosus, in which the proportion of fused individuals was greater in wave-exposed areas. In addition, interestingly, our ordination analyses showed that plant density could be effectively differentiated according to the morphology of the stipes. As suggested by Novoplansky (2009), plant morphology can be modified as a response to competition in contrasting densities.

Our results suggest that the quality of the environment for L. berteroana influences both the occurrence and composition of the POs and stipe-to-stipe intra-plant morphology. High density implies intra-specific competition for substrate and light. Concordantly, a positive correlation between mortality of recruits and plant density has been reported for other algae (e.g. of the genus Fucus, Steen \& Scrosati 2004). As the presence of adult conspecifics inhibits recruitment (Santelices \& Ojeda 1984), fusion poses an additional challenge to each individual genotype, by potentially adding intra-plant competition on top of intra-population competition. A precise evaluation of intra-specific competition between genets within and between plants is necessary to further understand the balance between environmental quality and intra-specific competition.

Finally, our results add complexity to demographic studies in L. berteroana that thus far have considered the whole plant as the individual entity (e.g. Ojeda \& Santelices 1984; Santelices \& Ojeda 1984). Our finding suggests than rather than the whole plant, it is important to con- 
sider the stipes, which would take into account the possible differences amongst genets within a clump.

\section{Kin aggregation}

An important result of this study is the observation that genotypes sharing a holdfast were more genetically related than on average in the population. This kin aggregation is not expected under the paradigm of stochastic spore settlement (i.e. with no choice of settlement site). However, kin aggregation is increasingly being detected in coastal species, including sessile (Veliz et al. 2006) and mobile invertebrates (Selkoe et al. 2006), providing evidence that mixing of propagules in the water column is less extensive than previously considered.

At least three non-exclusive hypotheses could explain this strong trend, each as post-settlement processes. First, higher R-values can result from fusions between sporophytes sharing the same mother and multiple fathers (siblings or half-siblings). Vegetative ramification and multiple egg production of the female gametophyte is a common process in Laminariales (Muñoz et al. 2004; Nelson 2004). To determine whether genotypes do correspond to full or half-sibs, a higher number of loci than studied here would be required in order to reduce the large sampling variance that lowers the precision of estimated relatedness (Lynch \& Ritland 1999). Second, dispersal and settlement may be non-random. Kin-structured dispersal (the joint dispersal of seeds or juveniles that come from the same family or the same mother) is an example of process that leads to kin aggregation in the adult stage. It explains some cases of smallscale genetic structure in plants (Torimaru et al. 2007) and genetic patchiness in marine invertebrates (Johnson \& Black 1982). Such dispersal modes have been reported in some seaweeds that bear unitary reproductive organs like the cystocarp in red algae, which can release bunches of spores surrounded by their maternal mucilage that keeps the spores together until settlement (Aedo 2007). This phenomenon seems unlikely to apply to kelps, which release motile spores individually that can hardly maintain proximity with their relatives because of the turbulence of the coastal waters where they are released.

The third hypothesis argues that dispersal and settlement are random but survival of the young sporophytes is determined by the genetic relatedness of the surrounding individuals. If fusions between genets are environmentally mediated, it is possible that aggregation between relatives provides higher benefits to the PO than non-kin aggregates would. This scenario is possible whenever intra-plant competition is reduced by the genetic relatedness of individuals sharing the holdfast. This is particularly noteworthy because it opens up a potential role of selection in determining the occurrence of kin aggregations within plants. It is not necessarily kin selection as it is known for social animal species, particularly because the existence of high relatedness amongst interacting individuals is not by itself sufficient evidence that kin selection is the driving force (Griffin \& West 2002). In the case of L. berteroana, genotypes within a kin aggregate may have a higher survival up to the adult stage than those within non-kin aggregates, as evidenced by the predominance of POs in LD areas, suggesting that kin aggregation brings fitness advantages over random interaction. In this context, every life history trait that favours the fusion between relatives to form a PO should be selected for, including traits at the group level (File et al. 2013). Such multi-level selection (Wilson 1997) on group-living traits in kelps is an interesting and testable hypothesis that emerges from the pattern observed in this study.

\section{Perspective: fusion of individuals as an adaptive strategy}

Traditionally, Lessonia berteroana has been considered as a unitary, aclonal species (sensu Santelices 1982), wherein each plant corresponds to one individual (e.g. Ojeda \& Santelices 1984; Santelices \& Ojeda 1984). Here, we have shown that one organism, made up of a single holdfast and a variable number of stipes and fronds can be composed of one or more individuals, and large kelps are most likely colonies of different genets. As several other inter-tidal species of red and green algae share this fusion capacity, it is possible that the phenomenon of coalescence in algae is an adaptation to highly stressful and heterogeneous environments such as the marine inter-tidal rocky shore. Direct benefits (i.e. higher survival, protection of the recruits) to the individual genet when integrated within a PO lead to the question whether fusion or coalescence is an adaptive strategy. This may be difficult to answer because it requires characterization of the traits of the PO that influence the individual genet, as well as the relative contribution of the traits of the PO and of the individual genet to the fitness of the genet. It also requires measurement of the exact costs and benefits of being part of a PO. So far, we have shown that the number of stipes of the PO is correlated with the number of genotypes, and that at LD stipes tend to be thinner than HD. The number of stipes is a good indicator of the reproductive potential for L. berteroana (Santelices \& Ojeda 1984), and therefore the observed morphological differences could mean fitness differences in terms of reproductive success.

At the individual level, a higher number of stipes in a PO may indicate that the trade-off between sharing the holdfast and the opportunity to produce external structures (the stipes) is reduced, as opposed to a situation in 
which the number of stipes was fixed by external factors. The predominance of POs in LD areas suggests that benefits largely exceed the eventual costs of sharing a holdfast, despite the plants tending to be smaller in LD than in HD areas. Better evaluation of these trade-offs (e.g. by quantifying the number of stipes that each genotype is able to produce within a shared holdfast, compared with a solitary holdfast) would allow an exact assessment of these costs and benefits at the individual level.

Santelices (1999) showed that genetic homogeneity and uniqueness as well as physiological autonomy of algae, are relevant criteria to define an individual. In this context, the limits of an individual, as a functional basic unit of organization, may vary according to the questions addressed, the approach developed and the model organism (Pepper \& Herron 2008). For example, ramets, clones, colonies and clumps can be defined as individual organisms, although none of these would fit into the more traditional unitary organism concept (Santelices 1999). Although an important debate is still ongoing around universal definitions of individual and organism (Nachtomy et al. 2002; Santelices 1999; Pepper \& Herron 2008 among others), the ecological and evolutionary implications of different ways of organization have received relatively little attention. The propensity of most species to form groups has been considered as an adaptation that may maximize the inclusive fitness of the individual genotype. The adaptation of these concepts traditionally used in social animals to non-animal models is a most challenging perspective of the study of plurigenotypic organisms.

\section{Acknowledgements}

The authors thank Alonso Vega, Nicole Piaget, Alfonso Gonzalez, Horacio Bastías and Cristian Jofré for fieldwork assistance; Raúl Vera and Javier Tapia for laboratory assistance; and Marcelo Rivadeneira, Jacqui Shykoff and Florence Tellier for valued comments that improved this manuscript. This study was partially supported by FONDECYT 1090742 to S.F. and CEAZA and INCAR (FONDAP 15110027) to P.H.

\section{References}

Aedo D. (2007) Esporas de algas rojas coalescentes y no coalescentes: diferencias funcionales y factores ambientales afectado la coalescencia. PhD thesis, Departamento de Ciencias Biológicas, Pontificia Universidad Católica de Chile, Santiago, Chile.

Andrew N.L., Viejo R.M. (1998) Effects of wave exposure and intraspecific density on the growth and survivorship of Sargassum muticum (Sargassaceae: Phaeophyta). European Journal of Phycology, 33, 251-258.
Avila M., Hoffmann A.J., Santelices B. (1985) Interacciones de temperatura, densidad de flujo fotónico y fotoperiodo sobre el desarrollo de etapas microscópicas de Lessonia nigrescens (Phaeophyta, Laminariales). Revista Chilena de Historia Natural, 58, 71-82.

Biedrzycki M., Jilany T., Dudley S., Bais H. (2010) Root exudates mediate kin recognition in plants. Communicative and Integrated Biology, 3, 1-8.

Blanchette C.A. (1997) Size and survival of intertidal plants in response to wave action: a case study with Fucus gardneri. Ecology, 78, 1563-1578.

Bolker B.M., Brooks M.E., Clarck C.J., Geange S.W., Poulsen J.R., Henry M., White J.S.S. (2008) Generalized linear mixed models: a practical guide for ecology and evolution. Trends in Ecology and Evolution, 24, 127-135.

Broitman B.R., Navarrete S.A., Smith F., Gaines S.D. (2001) Geographic variation of southeastern Pacific intertidal communities. Marine Ecology Progress Series, 224, 21-34.

Camus P. (1994) Recruitment of intertidal kelp Lessonia nigrescens Bory in northern Chile: successional constraints and opportunities. Journal of Experimental Marine Ecology, 184, 171-181.

Crawley M.J. (2005) Statistics: An Introduction Using R. Wiley, New York: 342pp.

Dayton P.K. (1975) Experimental evaluation of ecological dominance in a rocky intertidal algal community. Ecological Monographs, 45, 137-159.

Dayton P.K., Currie V., Gerrodette T., Keller B., Ronsenthal R., Tresca D.V. (1975) Patch dynamics and stability of some southern California kelp communities. Ecological Monographs, 54, 253-289.

Faugeron S., Véliz D., Peralta G., Tapia J., Tellier F., Billot C., Martínez E. (2009) Development and characterization of nine polymorphic microsatellite markers in the Chilean kelp Lessonia nigrescens. Molecular Ecology Resources, 9, 937-939.

File A.L., Murphy G.P., Dudley S.S. (2013) Fitness consequences of plants growing with siblings: reconciling kin selection, niche partitioning and competitive ability. Proceedings of the Royal Society B, 279, 209-218.

Gerlach G., Hodgins-Davis A., MacDonald B., Hannah R. (2007) Benefits of kin association: related and familiar zebrafish larvae (Danio rerio) show improved growth. Behavioral Ecology and Sociobiology, 61, 1765-1770.

González A., Santelices B. (2008) Coalescence and chimerism in Codium (Chlorophyta) from central Chile. Phycologia, 47, 468-476.

González A., Beltrán J., Hiriart-Bertrand L., Flores V., de Reviers B., Correa J.A., Santelices B. (2012) Identification of cryptic species in the Lessonia nigrescens complex (Phaeophyceae, Laminariales). Journal of Phycology., 48, 1153-1165.

Griffin A.S., West S.A. (2002) Kin selection: fact and fiction. Trends in Ecology and Evolution, 17, 15-21. 
Grueber C.E., Nakagawa S., Laws R.J., Jamieson I.G. (2011) Multimodel inference in ecology and evolution: challenges and solutions. Journal of Evolutionary Biology, 24, 699-711.

Hamilton W.D. (1964) The genetical evolution of social behaviour. I. Journal of Theoretical Biology, 7, 1-16.

Hoffmann A.J., Santelices B. (1997) Flora Marina de Chile Central. Ediciones Pontificia Universidad Católica de Chile, Santiago: 434pp.

Johnson M.S., Black R. (1982) Chaotic genetic patchiness in an intertidal limpet, Siphonaria sp. Marine Biology, 70, 157164.

de Kroon H. (2007) Ecology: how do roots interact? Science, 318, 1562-1563.

Lizé A., Khidr S.K., Hardy I.C.W. (2012) Two components of kin recognition influence parasitoid aggression in resource com- petition. Animal Behaviour, 83, 793-799.

Lynch M., Ritland K. (1999) Estimation of pairwise relatedness with molecular markers. Genetics, 152, 1753-1766.

Malm T., Kautsky L. (2004) Are Bladderwrack (Fucus vesiculosus L.) holdfasts that support several fronds composed of one or several genetic individuals? Aquatic Botany, 80, 221-226.

Martínez E., Santelices B. (1998) Selective mortality on haploid and diploid microscopic stages of Lessonia nigrescens Bory (Phaeophyta, Laminariales. Journal of Experimental Marine Biology and Ecology, 229, 219-239.

Martínez E., Cárdenas L., Pinto R. (2003) Recovery and genetic diversity of the intertidal kelp Lessonia nigrescens (Phaeophyceae) 20 years after EL NIÑO 1982/83. Journal of Phycology, 39, 504-508.

Muñoz V., Hernandez-Gonzalez M.C., Buschmann A., Graham M.H., Vásquez J.A. (2004) Variability in per capita oogonia and sporophyte production from giant kelp gametophytes (Macrocystis pyrifera, Phaeophyceae). Revista Chilena de Historia Natural, 77, 639-647.

Nachtomy O., Shavit A., Smith J. (2002) Leibnizian organisms, nested individuals, and units of selection. Theory in Biosciences, 121, 205-230.

Nelson W.A. (2004) Life history and growth in culture of the endemic New Zealand kelp Lessonia variegata J. Agardh in response to differing regimes of temperature, photoperiod and light. Journal of Applied Phycology, 17, 23-28.

Novoplansky A. (2009) Picking battles wisely: plant behaviour under competition. Plant, Cell and Environment, 32, 726741.

Ojeda F.P., Santelices B. (1984) Ecological dominance of Lessonia nigrescens (Phaeophyta) in central Chile. Marine Ecology Progress Series, 16, 83-91.

Paine R. (1990) Benthic macroalgal competition: complications and consequences. Journal of Phycology, 26, $12-17$.

Peakall R., Smouse P. (2006) GENEALEX 6: genetic statistic analysis in Excel. Population genetic software for teaching and research. Molecular Ecology Notes, 6, 288-295.
Pepper J.W., Herron M.D. (2008) Does biology need an organism concept? Biological Reviews, 83, 621-627.

R Core Team (2013) R: A Language and Environment for Statistical Computing. R Foundation for Statistical Computing, Vienna, Austria. http:/www.R-project.org/.

Ritland K. (1996) Estimators for pairwise relatedness and individual inbreeding coefficients. Genetics Research, 67, 175-185.

Rodriguez D., Oróstica M.H., Vásquez J.A. (2014) Coalescence in wild organisms of the intertidal population of Lessonia berteroana in northern Chile: management and sustainability effects. Journal of Applied Phycology, 26, 11151122.

Santelices B. (1982) Bases biológicas para el manejo de Lessonia nigrescens (Phaeophyta Laminariales) en Chile Central. Monografías Biológicas, 2, 135-150.

Santelices B. (1999) How many kind of individuals are there? Trends in Ecology and Evolution, 14, 152-155.

Santelices B. (2001) Implications of clonal and chimeric-type thallus organization on seaweed farming and harvesting. Journal of Applied Phycology, 13, 153-160.

Santelices B. (2004) A comparison of ecological responses among aclonal (unitary), clonal and coalescing macroalgae. Journal of Experimental Marine Biology and Ecology, 300, 31-64.

Santelices B., Aedo D. (2006) Group recruitment and early survival of Mazzaella laminarioides. Journal of Applied Phycology, 18, 583-589.

Santelices B., Alvarado L. (2008) Demographic consequences of coalescence in sporeling populations of Mazzaella laminaroides (Gigartinales, Rhodophyta). Journal of Applied Phycology, 44, 624-636.

Santelices B., Ojeda F.P. (1984) Recruitment, growth and survival of Lessonia nigrescens (Phaeophyta) at various tidal levels in exposed habitats of central Chile. Marine Ecology Progress Series, 19, 73-82.

Santelices B., Correa J., Meneses I., Aedo D., Varela D. (1996) Sporeling coalescence and intraclonal variation in Gracilaria chilensis (Gracilariales, Rhodophyta). Journal of Phycology, 32, 313-322.

Santelices B., Correa J., Aedo D., Flores V., Hormazabal M., Sanchez P. (1999) Convergent biological processes in coalescing Rhodophyta. Journal of Phycology, 35, 1127-1149.

Santelices B., Aedo D., Hormazabal M., Flores V. (2003) Field testing of inter- and intraspecific coalescence among midintertidal red algae. Marine Ecology Progress Series, 250, 91103.

Selkoe K.A., Gaines S.D., Caselle J.E., Warner R.R. (2006) Current shifts and kin aggregation explain genetic patchiness in fish recruits. Ecology, 87, 3082-3094.

Steen H., Scrosati R. (2004) Intraspecific competition in Fucus serratus and F. evanescens (Phaeophyceae: Fucales) germings: effects of settlement density, nutrient concentration, and temperature. Marine Biology, 144, 61-70.

Torimaru T., Tani N., Tsumura Y., Nishimura N., Tomaru N. (2007) Effects of kin-structured seed dispersal on the genetic 
structure of the clonal dioecious shrub Ilex leucoclada.

Evolution, 61, 1289-1300.

Vadas R.L., Wright A.W., Miller S.L. (1990) Recruitment of Ascophyllum nodosum: wave action as a source of mortality. Marine Ecology Progress Series, 61, 263-272.

Vadas R.L., Johnson S., Norton T.A. (1992) Recruitment and mortality of early t-settlement stages of benthic algae. British Phycological Journal, 27, 331-351.

Van Oosterhout C., Hutchisnson W.F., Willis D.P.M., Shipley P. (2004) Micro-checker: software for identifying and correcting genotyping errors in microsatellite data. Molecular Ecology Notes, 4, 535-538.

Vásquez J.A. (1991) Variables morfométricas y relaciones morfológicas de Lessonia trabeculata Villouta \& Santelices 1984, en poblaciones submareales del Norte de Chile. Revista Chilena de Historia Natural, 64, 271-279.

Vásquez J.A. (1992) Lessonia trabeculata, a subtidal bottom kelp in northern Chile: a case of study for a structural and geographical comparison. In: Seeliger U. (Ed.), Coastal Communities of Latin America. Academic Press Inc., San Diego: 392pp.

Vásquez J.A. (1995) Ecological effect of brown seaweed harvesting. Botanica Marina, 38, 251-257.

Vásquez J.A., Buschmann A. (1997) Herbivory-kelp interactions in subtidal Chilean communities: a review. Revista Chilena de Historia Natural, 70, 41-52.
Vásquez J.A., Santelices B. (1984) Comunidades de macroinvertebrados en discos de adhesion de Lessonia nigrescens en Chile central. Revista Chilena de Historia Natural, 57, 131-154.

Vásquez J.A., Santelices B. (1990) Ecological effects of harvesting Lessonia (Laminariales, Phaeophyta) in central Chile. Hydrobiologia, 204, 41-47.

Vásquez J.A., Tala F., Vega J.M.A., Zuñiga S., Edding M., Piaget N. (2008) Bases ecológicas y evaluación de usos alternativos para el manejo de praderas de algas pardas de la III y IV regiones. Final Report FIP 2005-22.

Veliz D., Duchesne P., Bourget E., Bernatchez L. (2006) Genetic evidence for kin aggregation in the intertidal acorn barnacle (Semibalanus balanoides). Molecular Ecology, 15, 4193-4202.

Wernberg T. (2005) Holdfast aggregation in relation to morphology, age, attachment and drag for the kelp Ecklonia radiata. Aquatic Botany, 82, 168-180.

Wilson D.S. (1997) Introduction: multilevel selection comes of age. American Naturalist, 150, S1-S4.

Wu C.C., Diggle P.K., Friedman W.E. (2013) Kin recognition within a seed and the effect of genetic relatedness of an endosperm to its compatriot embryo on maize seed development. Proceedings of the National Academy of Sciences of the United States of America, 110, 2217-2222. 